derivations are given, yet this information is exactly what the intelligent student needs in order to grasp the relevant scientific principles. In the same chapter, hydrographic features of estuaries are not fully discussed in terms of estuary size and salinity fluctuation, while recent work on the importance of rate of change of estuarine variables on the tolerance of animal species is not mentioned. Indeed the diagrams showing species penetration into estuaries are related to "salinity", not even "mean salinity" and certainly without reference to fluctuation.

Insufficient consideration is given to estuarine topography especially the influence of coastal emergence and submergence on estuarine form. The book as a whole deals almost exclusively with British and eastern American coasts, omitting any consideration of Arctic and tropical estuaries. In regard to the historical perspective of the subject, it fails dismally. The names of Bowden, Ketchum and Redfield, and Riley never appear, while in the place of the original figure depicting the mid-estuarine minimum in faunal diversity, given by Alexander et al. in their classical paper of 1935 , the author quotes only from his own book of 1971 .

The book includes a useful accumulation of productivity data for estuaries, with many food web diagrams, but little of novelty or abstracted wisdom which cannot be found elsewhere. The reference lists do not appear to be selective or exhaustive.

John Gray's Ecology of Marine Sediments, though less weighty in information, contains the essential material for the author's purpose and a good historical background. It aims to focus the minds of benthic ecologists on the interpretation of data in terms of modern ecological principles. Gray seizes on the linearity of the log-normal distribution of individual numbers in relation to species as a good measure of community equilibrium in the absence of disturbance. One would like to have seen a further extension of the philosophical basis of the idea, with a guess at the ecological meaning of the relevant statistics.

The book contains thoughtful discussions on niches, diversity and faunal stability - ideas that are currently being tested by ecologists in many environments. Finally, the author considers practical means of monitoring benthic communities in respect of long-term effects of pollution or of other factors that may control their structure.

This volume affords good reading for the above-average student of marine ecology who is prepared to sit and reflect, and is essential for those engaged in research on the fauna of sediments. It is a valuable contribution to ecological theory.

D.J. Crisp is Professor of Marine Biology at the Marine Science Laboratories, Menai Bridge, Gwynedd.

\title{
Aspects of environmental physiology
}

\section{J.A. Riegel}

Functional Adaptations of Marine Organisms. Edited by F. John Vernberg and Winona B. Vernberg. Pp.347. ISBN 0-12-718280-2. (Academic: 1981.) \$39.50, £26.20. Animal Osmoregulation. By J.C. Rankin and J. Davenport. Pp.202. Hbk ISBN 0-216-91014-5; pbk ISBN 0-21691015-3. (Blackie/Wiley: 1981.) Hbk $£ 17.95, \$ 39.95$; pbk £8.95.

THESE two books have one common feature: they represent attempts to relate various aspects of organismal function to environmental variables. That edited by the Vernbergs is a multi-authored treatise whose main use will be as a source of reference. Rankin and Davenport's book is much more didactic in its approach, and it should find a wide audience amongst students and teachers of courses in environmental physiology.

Functional Adaptations of Marine Organisms contains chapters written by specialists on primary production, bacteria, zooplankton, meiofauna, benthic macrofauna, pelagic macrofauna and deep-sea organisms. In addition, the editors have provided an introductory chapter describing the ecological subdivisions of the marine habitat. This is both welcome and necessary for the nonspecialist reader. Like most multi-authored works, however, the book's coverage is inadequate. For example, the discussion of zooplankton is confined to copepods, and primary producers are reviewed largely from an ecological viewpoint. Recent discoveries of communities of animals densely clustered around deep-sea, warmwater vents and dependent upon the primary production of chemosynthetic bacteria receive only brief mention. Nevertheless, the major shortcoming of the book is due to the inadequacy of the background data. Although more could have been done to round out the material, this deficiency is not altogether the authors' (or editors') fault - precious little is really known about the functional adaptations of marine organisms, especially those in the lessaccessible parts of the sea.

Despite its shortcomings, the book should be a useful reference work for specialists and non-specialists alike. Although no chapter represents an exhaustive review of the literature, most authors have included references to reviews and papers covering aspects of their subjects not discussed extensively in their contributions.

Animal Osmoregulation presents a refreshingly uncluttered overview of not only the basic concepts of the subject, but also most of the currently-active fields of research. The book starts with a consideration of basic principles, the explanations of which should be of sufficient clarity to be understood readily by the average under- graduate. Following this come discussions of the adaptations of animals to various habitats, from the sea to brackish water, fresh water and land. Specialized adaptations of osmoregulatory mechanisms, such as the mammalian kidney, buoyancy and to life in acid and alkaline waters, are also covered. The examples used to illustrate the various adaptations are highly selective and several are drawn from the research of the authors and their associates. Perhaps it is this personal experience of much of the research underlying the material which gives the narrative an admirable lack of dogmatism. Aware of the highly-variable nature of most data, they tend to generalize with caution.

The final chapter of Animal Osmoregulation deals with some of the common physiological and behavioural techniques used in studies of osmoregulation. The description of physiological techniques may provide useful background, but the short discussion of behavioural techniques should prove more valuable, especially as the basis of classroom experiments or demonstrations.

J.A. Riegel is a Reader in Zoology at Westfield College, University of London.

\section{Adaptation to supply and demand}

\section{Garth Chapman}

Animal Physiology: Adaptations in Function. By F. Reed Hainsworth. Pp.669. ISBN 0-201-03401-8. (Addison-Wesley: 1981.) $\$ 25.95, £ 10.95$.

HaInsworth's Animal Physiology declares itself to be ecological and comparative by its subtitle but only discloses the fact that it is "organized around" an "economic theme for comparative physiology" in the preface. The animal's balance sheet of benefits and costs uses the currency of resources and concludes about joules and survival what Mr Micawber concluded about pence and happiness.

This is certainly an important theme but it becomes a little tedious by reiteration. However heuristically valuable such an approach may be when applied to resources such as oxygen, food, water and salts, it is less directly applicable to that large and distinctive part of animal physiology which is concerned with reception, co-ordination and response. Accordingly, perhaps, the section dealing with these topics is placed at 